\title{
LECCIONES PAULINAS PARA EL EVANGELISMO ACTUAL
}

Torres Salazar, Abel C. Universidad Peruana Unión abeltorres@teologia.edu.pe

Fecha de recepción: Abril 2013 Fecha de aceptación y versión final: Junio 2013

\section{Resumen}

Pablo tuvo la certeza de su llamado para el ministerio apostólico; él comprendió claramente la naturaleza de esta tarea y fue diligente en el cumplimiento de todas las instrucciones que recibió de parte del Señor. El convencimiento de su llamado lo fortaleció a través de cada prueba. El entendimiento de la naturaleza precisa de la tarea que tenía que realizar le permitió aplicarse a sí mismo con gran flexibilidad. El poseer, a la vez, un profundo sentido de responsabilidad para con su comisión, fue la fuerza motivadora que estuvo detrás del cumplimiento de su tarea. En las cartas que escribió para las diferentes iglesias, encontramos que Pablo describe su ministerio pastoral y apostólico con una variedad de lecciones. En este artículo, se considerará algunas de ellas, para obtener una imagen bíblica del evangelismo para estos tiempos. Cada lección está centrada en Cristo, y describe un aspecto particular del ministerio de la evangelización.

Palabras claves: Evangelismo, servicio, adaptación, responsabilidad, gratitud. 
Summary: $\quad$ Paul was certain of his call to the apostolic ministry; he clearly understood the nature of this task and was diligent in complying with any instructions received from the Lord. The conviction of his call was strengthened through every difficulty he encountered. The understanding of the precise nature of the task he had to perform allowed him to apply himself with great flexibility. Possessing a deep sense of responsibility to his commission was the motivating force behind the fulfillment of his task. In his letters he wrote to various churches, we find that Paul describes his pastoral and apostolic ministry with a variety of lessons. In this article, we will analyze some of them to get a biblical position on evangelism for our times. Each lesson is centered on Christ and describes a particular aspect of the ministry of evangelization.

Keywords: Evangelism, service adaptation, responsibility, gratitude. 


\section{Introducción}

Pablo es el apóstol a los gentiles, aparece en el libro de Hechos como el fundador de iglesias y, en sus cartas, como un pastor devoto, un hábil polemista y un amigo sincero de los cristianos, revelando un encendido espíritu por el amor de Cristo como un gran evangelista. Es a través de sus cartas que también Pablo destaca como un influyente teólogo de la era apostólica. ${ }^{1}$

En ese sentido, como parte del proceso de desglosar las lecciones paulinas para el evangelismo actual, en el contexto distintivo de su teología misionera, es necesario ir más allá de lo que se denomina su estrategia misionera y su motivación. Por lo tanto, es imposible aislar un elemento específico como el motivo fundamental de la teología de Pablo, pues la vida de Pablo fue una vida de actividades intensas y variadas. De ciudad en ciudad y de país en país, él viajaba, con-

1 E. F. Harrison, "Pablo y paulinismo", en Diccionario de Teología, eds. E. F. Harrison, G. W. Bromiley, y C. F. H. Henry (Grand Rapids, MI: Libros Desafío. 2006), 441. tando la historia de la cruz, ganando conversos para el evangelio y estableciendo iglesias. ${ }^{2}$

Es por eso que se debiera sentir ahora la responsabilidad de trabajar con intenso fervor, en impartir a otros las verdades que Dios ha dado para este tiempo. Por otro lado, las epístolas del apóstol Pablo forman aproximadamente cincuenta por ciento del Nuevo Testamento. Desde sus viajes misioneros hasta su encarcelamiento en Roma, vemos que Pablo hizo y sufrió todo por el evangelio. Las enseñanzas y lecciones de Pablo nos ayudan a entender las verdades fundamentales del cristianismo, el cómo se vive la fe cada día y cuáles son los deberes de una iglesia en el evangelismo actual.

\section{Lecciones paulinas}

\section{Evangelista presto al servicio}

"Porque aunque soy libre de todos los hombres, me hice esclavo de todos para ganar a la mayor

2 Elena G. de White, El evangelismo (Buenos Aires: Asociación Casa Editora Sudamericana, 1975), 57. 
cantidad posible". (1 Cor 9:19).

La libertad ${ }^{3}$ es un concepto relativo que tiene sus propias limitaciones. Pablo no dice que es libre de todas las cosas, sino que es libre de todos los hombres. Hace eco a la idea que empezó en el capítulo (v. 1), pues allí afirma que es libre porque tiene libertad cristiana. Aquí declara que es libre de todos los hombres, como hecho objetivo, ya que no ha hecho uso de toda la libertad que posee.

Pablo dice que él tiene la libertad de comer o no comer carne, y que goza de independencia económica en virtud de su negocio de las carpas. Pero nunca estuvo libre de la ley de Dios, porque tenía libertad solo dentro del contexto de esa ley.

Como hombre libre, Pablo es capaz de relacionarse con cualquier creyente de la Iglesia de Corinto. Tiene plenos derechos apostólicos para estar

3 Real Academia Española, "Libertad", Diccionario de la lengua española 22. ${ }^{a}$ ed., http://www.rae.es/rae.html (consultado: 14 de abril, 2013). libre del control humano, pero escoge ser siervo de todos los creyentes de Corinto. Cumplió literalmente las palabras que Jesús dijo a sus discípulos:

"Como ustedes saben, los gobernantes de las naciones oprimen a los súbditos, y los altos oficiales abusan de su autoridad. Pero entre ustedes no debe ser así. Al contrario, el que quiera hacerse grande entre ustedes deberá ser su servidor, y el que quiera ser el primero deberá ser esclavo de los demás" (Mt 20:25-27).

Pablo imitaba a Jesús, quien vino a servir y no a ser servido.

Pablo se hace servidor de todos, con el fin de ganar a la mayor cantidad de gente para Cristo $^{4}$. Debe quedar claro que él no compite con otros apóstoles para ver quién convierte más gente a Cristo. Más bien, espera que la estrategia de ser siervo de todos traiga más gente a Cristo que cualquier otro método, al ponerse al servicio del pueblo

4 Andrés Robert, Conciencia misionera II (Barcelona: Comibam Internacional, 2005), 153. 
de Cristo, Pablo demuestra que es un siervo de Jesús.

\section{Un evangelista que adap- taba su predicación}

"Con los judios me comporto como judio, para ganar a los judios. Para los que están bajo la ley me he convertido como uno que está bajo la ley, aunque yo mismo no esté bajo la ley, para ganar a los que están bajo la ley". (1 Cor 9:20).

Pablo menciona "con los judíos me comporto como judío, para ganar a los judíos”. Como aquel que es siervo de todos, $\mathrm{Pa}$ blo empieza por su propia gente y se apega al principio de "a los judíos primeramente y también a los gentiles". Pablo era judío y hebreo de hebreos (Fil 3:5). Pero cuando dice que se hace judío para los judíos, quiere decir que, al ser un seguidor de Jesús, vive en una nueva creación (2 Cor 5:17), que ya no es ni judío ni gentil.

En su intento de ganar a los judíos para Cristo, Pablo se adaptaba a las costumbres judías durante su ministerio ${ }^{5}$. Estos son algunos de los ejemplos notables: dejó que Timoteo fuese circuncidado "por causa de los judíos" (Hch 16:3); hizo un voto nazareo para expresar a Dios su agradecimiento (Hch 18:18); se purificó junto a cuatro nazareos y pagó sus gastos para la ofrenda sacrificial (Hch 21:23, 24, 26).

Pablo trató de promover la unidad de la Iglesia llevando hasta Jerusalén a algunos cristianos gentiles de Macedonia y Asia Menor (Hch 20:4). Aunque fue acusado de no enseñar la ley de Moisés a los judíos de la dispersión (Hch 21:20, 21), voluntariamente pacificó a los cristianos judíos de Jerusalén. Quería demostrar que no tenía ningún reparo en obedecer la ley de Moisés.

Por otro lado, Pablo menciona "Para los que están bajo la ley me he convertido como uno que está bajo la ley, aunque yo mismo no esté bajo la ley”. Esta idea es paralela a la primera

5 Matthew Henry y Francisco Lacueva, Comentario bíblico de Matthew Henry (Barcelona: Editorial CLIE, 1999), 1699. 
oración del versículo. Ambas oraciones se aplican a los judíos que estaban bajo la ley de Moisés y a los cristianos con una conciencia débil ${ }^{6}$. ¿Pero por qué vuelve Pablo a llamar la atención a los judíos? Para hacer una clara distinción entre quienes estaban bajo la ley (v. 20) y quienes no estaban bajo la ley (v. 21), en la teología de Pablo, estar "bajo la ley" es justificarse por las "obras" y los que no están bajo la ley están bajo la "gracia" de Cristo. Para que una persona sea justa debe obedecer la ley de manera perfecta, pero el pecador es imperfecto ante la ley y no puede obtener justificación por las obras, para salir de este dilema, el pecador debe aceptar a Jesucristo por fe.

Como campeón de la libertad cristiana, Pablo pondrá de lado su libertad en Cristo y se someterá a la esclavitud de la ley mosaica. Esto lo hace en contextos judíos y solo por una razón:

6 Robert Jamieson, A. R. Fausset y David Brown, Commentary Critical and Explanatory on the Whole Bible (Oak Harbor, WA: Logos Research Systems, Inc., 1997), 345. ganar a los judíos para Cristo. Con todo, añade algo que aclara su disposición a guardar los mandamientos de la ley mosaica: "aunque yo mismo no esté bajo la ley”, es decir, Pablo está rechazando la ley como medio de justificación, pero no rechaza la obediencia de la ley como pecador justificado que vive en paz con Dios y camina en armonía con el Espíritu.

Sin embargo, cuando expresa "Para ganar a los que están bajo la ley". Lo que Pablo busca al obedecer la ley mosaica es promover la conversión de los judíos al cristianismo. No habla de los judíos cristianos que ya saben que en Cristo tienen libertad. Más bien, se refiere a los judíos que todavía no conocen a Jesús y el poder liberador del evangelio. Quiere que los que están bajo la ley, tengan la misma libertad que él goza en Cristo?

Aunque Pablo fue nombrado, ante todo, como apóstol de los gentiles (véase Gal 2:7-9),

7 Larry Richards y Lawrence O. Richards, The Teacher's Commentary (Wheaton, IL: Victor Books, 1987), 934. 
predicó el evangelio de salvación a judíos y gentiles (Hch. 20:21).

De esta forma buscó ganar a "los que están bajo la ley" y a "los que están sin la ley". Con esto, Pablo adaptaba sus mensajes tanto a judíos como a gentiles, para sacarlos a libertad del modo de vida que ellos llevaban, estando bajo la servidumbre de la ley, es decir tenían la forma pagana de vivir en esclavitud a las pasiones humanas. En ese sentido, Pablo adaptaba sus mensajes para rescatarlos del poder del maligno con la ayuda de Dios, darles libertad en Cristo para liberarlos de sus bajas pasiones; por medio de la fe, les mostraba la libertad en la obra de Cristo para que sean llevados a la redención y vivan un nuevo estilo de vida en Cristo.

\section{Un evangelista incansable para la predicación}

"Para los que no tienen la ley me he convertido como uno que no tiene la ley, aunque yo mismo no esté sin la ley de Dios sino bajo la ley de Cristo, para ganar a los que están sin la ley". (1 Cor 9:21).

Pablo amaba en gran manera a su pueblo, a los judíos. La Biblia menciona que Dios lo envió al mundo de los gentiles (los no judíos) con el evangelio de Jesús, predicando en las sinagogas de judíos, pero como apóstol de los gentiles extendió el cristianismo por toda Asia menor y el mundo occidental. En consecuencia, el apóstol se destaca por ser un estratega en el sentido de la misión evangélica. Sus viajes se realizan sin tener una dirección clara, primero escuchando la voz del Señor por medio del Espíritu Santo y siguiendo las vías principales por donde transitaba la gente, así como las ciudades clave para que de allí se extendiera el evangelio. En su primer viaje misionero se lo ve tomando una vía que él conocía, llegando a ciudades importantes, lo mismo en su segundo y tercer viajes. No se lo ve fundando iglesias por fundarlas, sino que lo hace con el fin de que estas pudieran, a su vez, extender la Palabra a través de los creyen- 
tes. La estrategia funcionó en vista de que en poco tiempo los pobladores del Imperio romano conocían el evangelio, gracias a las comunidades cristianas que se iban formando. ${ }^{8}$

Pablo, como misionero, fue incansable. Manejó muy bien su vida, donde su trabajo era alternado con la organización de grupos de creyentes. Su fe y sus convicciones le llevaron hasta el propio palacio del César, ofrendando su vida por causa del evangelio. Pablo nos dejó lecciones en su vida como ejemplo para el evangelismo de estos tiempos.

Pablo había asumido el compromiso de su ministerio en anunciar a Cristo Jesús, "amonestando a todo hombre, y enseñando a todo hombre en toda sabiduría, a fin de presentar perfecto en Cristo Jesús a todo hombre. Para esto también trabajó, luchando según la fuerza de Él, la cual actúa poderosamente en mí". (Col 1:28-29) su

8 J. C. Cevallos, Romanos, de Comentario bíblico mundo hispano (El Paso, TX: Editorial Mundo Hispano, 2006), 19:11. trabajo de formación consistía, al menos, en tres actividades: anunciar, amonestar y enseñar ${ }^{9}$ incansablemente. Es nuestra responsabilidad trabajar incansablemente, para alcanzar el máximo potencial en Cristo. Es un trabajo sacrificado. Pero no existe en la Iglesia otra actividad que le dé al líder tantas satisfacciones como el anunciar las buenas nuevas de salvación en Cristo.

\section{Un evangelista con un servicio real a la misión}

"A los débiles me he hecho débil para ganar a los débiles. A todos me he hecho de todo para que por todos los medios salvar a algunos". (1 Cor 9:22).

"A los débiles me he hecho débil para ganar a los débiles". Pablo ahora vuelve a su discusión sobre los cristianos con conciencia débil (8:9-13). Pablo ha completado el círculo al revisar la libertad que tiene en Cristo, su relación para con el

9 C. Shaw, Alza tus ojos (San José, Costa Rica: Desarrollo Cristiano Internacional, 2005), 58. 
débil ${ }^{10}$ era mostrar el sacrificio de Cristo en la cruz entregándose a sí mismo para conceder libertad, en ese sentido la conducta cristiana es libertad, por lo tanto, cuando Pablo invita a los judíos y gentiles hacia la libertad en Cristo, era vivir una vida comprometida y muy justa, para que no tomen decisiones morales como esclavos de sus pasiones o reglas, sino como una persona libre en Cristo, esto lo identifica a Pablo como un evangelista con un servicio real a la misión de salvar al pecador.

Por otro lado, el versículo 22 da a entender que, en este pasaje particular, Pablo también podría haber estado pensando en ganar para el Señor a los corintios económicamente débiles ${ }^{11}$. Anteriormente, en la carta afirmó que entre aquellos que

10 Paul Barnett, The Second Epistle to the Corinthians, en New International Commentary of the New Testament (Grand Rapids: WM. B. Eerdmans Publishing, 1997), 662.

11E. F. Harrison, Pablo y paulinismo, en Diccionario de Teología, eds. E. F. Harrison, G. W. Bromiley y C. F. H. Henry (Grand Rapids, MI: Libros Desafío. 2006), 564.
Dios había llamado no había muchos poderosos, ni muchos de noble cuna, sino que Dios había escogido al débil e insignificante para avergonzar a los fuertes (1:26-28). Ahora Pablo hace resonar el mismo mensaje cuando escribe: "a los débiles me he hecho débil". En este contexto, usa el verbo ganar para hablar de llevar a judíos (vv. 19, 20) y gentiles (v. 21) al conocimiento de Cristo. Pero cuando habla de los débiles, cuya conciencia era débil, no usa el verbo ganar. Los débiles ya conocen a Jesucristo como Salvador, pero por tener una conciencia débil, necesitan la ayuda de los fuertes.

Creemos que con la oración me he hecho débil para ganar a los débiles (v. 22), Pablo podría estar comunicando una doble connotación. En otras palabras, se refiere a los débiles de conciencia y a los débiles económicamente. Hay que considerar que, al ministrar en Corinto, Pablo se identificó en palabra y hecho con los pobres. Su trabajo, fabricando carpas, era una clara demostración de que se ponía de lado de los económi- 
camente débiles (Hch 18:1-4). Pablo mismo pertenecía a la clase alta, como lo demuestra la educación que recibió. Sin embargo, no tenía ningún reparo en ponerse un delantal y gorro para trabajar en su rubro. La alta sociedad grecorromana lo despreciaría por su denigrante trabajo, pero la clase baja lo aceptaría gustoso. La clase alta pensaba que el taller no era un lugar para el hombre libre, sino para el esclavo. Con todo, Pablo estaba listo a identificarse con el pobre para ganarlos para Cristo.

"A todos me he hecho de todo para por todos los medios salvar a algunos". El apóstol es un modelo para todo el que quiere ganar gente para Cristo. Pablo se acomodaba a las diferentes situaciones de cada cultura. Con los judíos vivía como judío, y con los gentiles como gentil (dentro de los límites del mandamiento de Cristo) ${ }^{12}$. Se hizo débil a los débiles, para así

12 Roberto Jamieson, A. R. Fausset y David Brown, Comentario exegético y explicativo de la Biblia: Tomo 2: El Nuevo Testamento (El Paso, TX: Casa Bautista de Publicaciones, 2002), 379. ser de todo para todos.

Los oponentes de Pablo podrían tildarlo de ineficaz, inestable y cambiante. En este caso, estarían mal entendiendo completamente sus motivaciones, al no darse cuenta de la intención misionera de los esfuerzos de Pablo: llevar al evangelio a la mayor cantidad de gente posible.

Pablo estaba convencido de que al predicar las buenas nuevas de salvación, Dios abriría el corazón de cada uno de los elegidos para salvación. Si a Dios le había placido salvar a Pablo, quien se llamaba a sí mismo el primero de los pecadores (1 Tim 1:15), el Señor Jesucristo podía entrar en el corazón de cualquiera que viviese en tinieblas. Pablo era un instrumento en las manos de Dios para traer a los pecadores al Señor mediante el evangelio. Pablo predicaba y aconsejaba, pero el verdadero trabajo de salvación pertenecía a Dios.

En pocas palabras, Pablo manifiesta un realismo sobrio. Por 
supuesto que Pablo sería el primero en afirmar que, aunque él trabajaba duro para presentar el evangelio a todos, solo Dios efectuaba la salvación (Flp 2:13). Trabajaba para salvar a todos, pero sabía que solo algunos responderían al evangelio.

\section{Un evangelista apasiona- do por el evangelismo}

"Y todo lo hago por el bien del evangelio, para participar conjuntamente en él". (1 Cor 9:23).

"Y todo lo que hago". Notemos que cuatro veces Pablo escribe la palabra todo en los versículos 22 y 23. Es un siervo humilde del evangelio, que irá a cualquier parte, que descenderá o ascenderá a cualquier nivel de la sociedad o hará cualquier tarea por insignificante que sea ${ }^{13}$, con tal que el evangelio sea proclamado a todos. Pablo no conocía la palabra discriminación, ya que decía que en Cristo no había "judío ni griego, esclavo ni libre, hombre ni mujer" (Gal 3:28). Sabía que en Cristo

13 Roberto Jamieson, 398. todos los creyentes son uno.

"Por el bien del evangelio". Esta afirmación repite lo dicho en los versículos 15-18. Pablo es un siervo del evangelio, tal como lo demuestra sirviendo a toda clase de gente. Solo piensa en la labor que el Señor le ha dado y que tiene que cumplir. Es la tarea de proclamar el pleno evangelio de la gracia de Dios a todos los seres humanos en todo lugar. Pablo estaba listo a viajar a Ilírico (lo que fue $\mathrm{Yu}$ goslavia y que ahora es Albania) y a España, para que el evangelio fuese lo más ampliamente divulgado (véase $\mathrm{Rm}$ 15:19, 24).

"Para participar conjuntamente en él”. Uno podría pensar que Pablo pierde, cuando afirma que su intención es servir a todos los que quieran escuchar el evangelio. Pablo no pierde, sino que se beneficia de las bendiciones que vienen con la predicación de las buenas nuevas $^{14}$. Cada vez que una persona

14 David S. Dockery, et al., Holman Bible Handbook (Nashville, TN: Holman Bible Publishers, 1992), 690. 
cree en Cristo, se produce gozo y felicidad en el Señor, y Pablo el heraldo del evangelio participa en esa gozosa celebración. Además, el predicar las buenas nuevas de salvación le trae una rica bendición.

Una traducción literal de esta parte del versículo 23, diría: “para coparticipar en Él”. La expresión coparticipar ${ }^{15}$ no apunta tanto a que Pablo participa con sus asociados en la labor de predicar, sino que participa en las bendiciones que reciben los que se convierten a Cristo. Pablo se regocija con ellos, al verlos tomar posesión de los beneficios espirituales que vienen de una vida obediente al evangelio.

Para el apóstol la predicación del evangelio de Cristo era su pasión, lo hacía predicando, proclamando, anunciando y enseñando, verbos que siempre son utilizados en sus cartas para mostrar la urgencia del mensaje que necesita el mundo que lo

15 S. J. Kistemaker, Comentario al Nuevo Testamento: 1 Corintios (Grand Rapids, MI: Libros Desafío, 1998), 332. rodea. ${ }^{16}$ Se sumergía profundamente en su tema y en su audiencia. El apóstol Pablo vivió apasionadamente por el trabajo misionero.

La pasión se origina en el corazón de Dios y se procesa en el corazón del hombre. Nuestro Dios es un fuego que consume, impresionante en poder. Cuando Él habla, la tierra tiembla. Si se desea sacudir los corazones de los hombres, entonces es necesario ser un canal a través del cual Dios pueda llegar a esos corazones. Se debe estar listo y preparado para ejecutar la voluntad de Dios. Cuando se está apasionado por Dios, entonces se está apasionado en la predicación ${ }^{17}$ tal como el apóstol $\mathrm{Pa}$ blo.

\section{Un evangelista con un sentido de preocupación por la misión}

La preocupación de Pablo, como evangelista, era mirar la

16 J. C. Cevallos, 14.

17 A. Montoya, Predicando con pasión (Grand Rapids, MI: Editorial Portavoz. 2003), 26. 
humanidad sin Cristo, totalmente extraviada, en camino a la perdición y en urgente necesidad de salvación. La idea del juicio inminente sobre los que "no obedecen la verdad" (Rm 2:8) es un tema reiterativo en Pablo. Precisamente por esto, no se permite un momento de descanso. Le urge proclamar, a cuantos sea posible, el rescate del "castigo venidero" (1 Tes 1:10). Pablo es embajador de Cristo. Dios apela a los perdidos a través del apóstol y de sus colaboradores: "En nombre de Cristo les rogamos que se reconcilien con Dios" (2 Cor 5:20).

La preocupación principal de la predicación de Pablo no es, sin embargo, "el castigo venidero". Nunca se ocupa de él detalladamente. El castigo de Dios es, más bien, el oscuro contraste del mensaje positivo que él proclama: la salvación en Cristo y el inminente triunfo de Dios. Su evangelio es buenas nuevas para personas que han pecado intencionalmente, que se encuentran sin excusa y que merecen el juicio de Dios, pero para quienes Dios, en su bondad, abre una oportunidad para el arrepen-

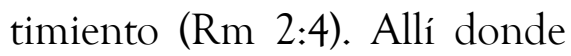
sus oyentes responden positivamente, dice Pablo en la primera carta que escribió, se convierten de los ídolos a Dios, "para servir al Dios vivo y verdadero" (1 Tes 1:9). "La conversión ha traído a los convertidos del reino de la muerte y la falsedad, al reino de la vida y la realidad de Dios". He aquí una metamorfosis mucho más fundamental que cualquier visión filosófica. Para Pablo la meta no es alcanzar el potencial natural, sino la formación de Cristo en el creyente. El propósito de la misión de Pablo, entonces, es llevar a las personas a la salvación en Cristo. Esta perspectiva antropológica, sin embargo, no es el objetivo final de su ministerio. En este y a través de este, Pablo está preparando al mundo para la gloria venidera de Dios y para el día cuando todo el universo lo adorará.

Por consiguiente, su preocupación por el cumplimiento de la misión lo llevó a Pablo a ver, con certeza, su llamado para el ministerio apostólico (misionero); él comprendió claramente la naturaleza de esta tarea y fue 
diligente en ver el alto grado de responsabilidad en el cumplimiento de todas las instrucciones que recibió de parte del Señor. El convencimiento de su llamado lo fortaleció a través de cada prueba. El entendimiento de la naturaleza precisa de la tarea que tenía que realizar, le permitió aplicarse a sí mismo con gran flexibilidad. El poseer, a la vez, un profundo sentido de una preocupación responsable para con su comisión, fue la fuerza motivadora para estar detrás del cumplimiento de su tarea ${ }^{18}$ en el marco de la salvación.

\section{Un evangelista con senti-} do de responsabilidad por la misión

La actitud de preocupación de Pablo hacia los gentiles del Imperio romano se demuestra en una profunda percepción de que su obligación es proclamarles el evangelio ${ }^{19}$. Es una responsabilidad puesta sobre sus hombros,

18 J. Lewis, Misión mundial, Tomo 1 (Miami, Fl: Editorial Unilit, 1990), 101.

19 Warren W. Wiersbe, The Bible Exposition Commentary (Wheaton, IL: Victor Books, 1996), 439. "jay de mí si no predico el evangelio!” (1 Cor 9:16). Involucrarse en la misión para Pablo es tener un alto sentido de responsabilidad.

Sin duda, la manera de predicar el evangelio que tiene Pablo se da en un marco de "flexibilidad, sensibilidad y empatía”, y que para él la misión no implica ni la "helenización" de los judíos ni la "judaización" de los grie$\operatorname{gos}^{20}$. No obstante, en este contexto, tal aspecto es periférico respecto a lo que Pablo dice. No está ofreciendo pautas para el ajuste misionero a una situación transcultural. La última frase de la cita demuestra "cuán poco tiene que ver este pasaje con el mero arte del ajuste o la técnica misionera exitosa. La libertad de su servicio no es opción suya: es cuestión de obediencia al evangelio, en tal grado que su propia salvación está en juego". En esencia, Pablo afirma dos cosas aquí: el evangelio de Jesucristo es para todos, sin distinción; y él, Pablo, está bajo la obligación de tratar de "ganar" a tantos como sea posible. Precisamente por esta razón, Pablo insiste en

20 Ibíd, 105. 
que no haya ninguna piedra de tropiezo puesta en el camino de los potenciales convertidos o de los creyentes "débiles".

Sin embargo, ganar el respeto y hasta la admiración de otros no es suficiente. El estilo de vida del cristiano no solo debe ser ejemplar, sino atractivo. Debe atraer a los de afuera e invitarlos a unirse a la comunidad. En otras palabras, los creyentes deben practicar una responsabilidad por la misión.

Pablo, como un evangelista con sentido de responsabilidad, se muestra como un verdadero pastor, cuidadoso y preocupado por su rebaño, dando gracias a Dios y orando constantemente por ellos, a la vez que por todos los medios se esfuerza físicamente para no ser una carga para ellos. ${ }^{21} \mathrm{Su}$ responsabilidad implicaba comunicar el mensaje de Dios con eficacia, exactitud y fidelidad, ${ }^{22}$ Pablo sabía que el

21 Piccardo, H. R., Introducción al cuerpo epistolar del Nuevo Testamento: Tomo 1 (Buenos Aires: Ediciones del Centro, 2006), 51.

22 J. I. Packer, El evangelismo y la mensaje proclamado, los hechos y las promesas del evangelio y el poder redentor de la muerte de Jesús en el Calvario, era el mensaje de Cristo. La imagen del embajador responsable hace resplandecer la autoridad que tenía Pablo para representar a Cristo.

En su obra de evangelista, con un sentido responsable, Pablo actuó como esclavo y mayordomo, como divulgador y pregonero, como representante y embajador del Señor Jesús. Así que fue valiente, autoritario y firme, frente a la burla y la indiferencia, asimismo, rehusó las posibilidades de modificar o alterar el evangelio frente a las demandas circunstanciales.

Estas dos actitudes gozaban de una liga íntima, pues Pablo se consideró representante fiel de Cristo cuando proclamaba el mensaje puro e inalterado de Dios. Pablo fue encomendado por Cristo a declarar su mensaje y, por lo tanto, habló con autoridad y con la responsabilidad de que la gente le oyera.

soberanía de Dios (Graham, NC: Publicaciones Faro de Gracia, 2008), 46. 
Un evangelista con un sentido de gratitud por la misión

Únicamente, a partir de este punto, podemos llegar al nivel más profundo de la motivación misionera de $\mathrm{Pa}$ blo. Él va hasta los confines de la tierra debido a la experiencia abrumadora del amor de Dios que ha recibido por medio de Jesucristo. "El Hijo de Dios...me amó y dio su vida por mí", escribe Pablo a los gálatas (Gal 2:20), y a los romanos les dice: "Dios ha derramado su amor en nuestro corazón” (5:5). La expresión clásica de la conciencia de Pablo, acerca del amor de Dios como una motivación para la misión, se encuentra en 2 Cor 5:23, pero en el versículo 11 afirma: "Por tanto, como sabemos lo que es temer al Señor, tratamos de persuadir a todos".

Como hemos demostrado, "temor" aquí se refiere al deseo de Pablo de no decepcionar a su amado Dueño. En el versículo

23 Ibíd., 59.
14 articula luego el lado positivo del versículo 11: "El amor de Cristo nos obliga”. Para Pablo, entonces, la razón más elemental por la cual proclama el evangelio a todos no es solo su preocupación por los perdidos, ni es primordialmente el sentido de obligación que le fue impuesto, sino un sentido de privilegio.

Por medio de Cristo, dice él, "Dios me ha concedido el privilegio de ser su apóstol, para que en todas las naciones haya quienes crean en Él y le obedezcan". Pablo emplea la palabra gratitud para describir su tarea misionera. La deuda u obligación que siente no representa una carga pesada; más bien, reconocer su deuda es sinónimo de acción de gracias. La manera que él tiene de dar gracias es ser misionero al judío y al gentil. El apóstol ha cambiado la terrible deuda del pecado por otra deuda: la deuda de gratitud, la cual se manifiesta en la misión, ${ }^{24}$ en ser un evangelista relevante, inclusive para nuestra actualidad.

24 C.R.Padilla, Basesbíblicas delamisión: Perspectivas latinoamericanas (Buenos Aires: Nueva Creación, 1998), 333. 
El apóstol Pablo era un hombre agradecido y constantemente impulsaba a las iglesias a poner en práctica esta virtud. ${ }^{25}$ ¡Cuán importante es que el cristiano manifieste siempre esta conducta cristiana! No se debe tomar lo que se recibe como si fuera una obligación o un privilegio del que lo da. "Toda buena dádiva" viene de Dios y se debe mostrar agradecimiento al Señor y a los instrumentos que él usa. Finalmente, una vida digna se caracteriza por acciones de gracias al Señor por todo lo que hace a favor de sus hijos. Al reconocer esto, tenemos que contemplar sus beneficios y agradecerle cada cosa que se recibe de Él. El resultado, entonces, es una actitud humilde, gozosa y agradecida. ${ }^{26}$

En ese sentido Pablo dice que, cuando se toma conciencia de nuestra herencia en Cristo, se responde "dando gracias al Padre" (Col 1:12); que, cuando

25 R. C. Zapat, Comentario bíblico del continente nuevo: Filipenses (Miami, FL: Editorial Unilit, 1996), 26.

26 R. Porter, Estudios bíblicos ELA: ¿Qué más quieres? (Puebla, México: Ediciones las Américas, 1990), 21. se está firmemente arraigado en Cristo, es normal que se "rebose en gratitud" (Col 2:7); y que, cuando la paz de Cristo reina en los corazones, se debe "ser agradecido" (Col 3:15); y exhorta a llevar a cabo todos los quehaceres "en el nombre del Señor Jesús, dando gracias por medio de Él a Dios el Padre" (Col. 3:17). ${ }^{27}$

En varias ocasiones Pablo, expresa su propia gratitud y anima a los creyentes a que sean agradecidos a Dios por el privilegio de participar en la misión evangélica.

\section{Conclusión}

Todavía queda mucho por decir sobre este tema tan vasto y valioso. Otros autores han hecho su contribución. Sin embargo, se ha cubierto suficiente terreno para ofrecerle una adecuada comprensión intelectual sobre las lecciones paulinas para el evangelismo actual. Ahora le toca a usted poner las manos en el arado y comenzar a

27 D. F. Burt, Deberes Domésticos y otros Asuntos: Colosenses 3:18-4:18 (Barcelona: Publicaciones Andamio, 2006), 108. 
aplicar lo aprendido en su contexto del evangelismo.

Practicar cada una de estas lecciones siempre permitirá a todo individuo vivir una vida que inspire a los demás, que los impulse a la grandeza del evangelismo. Muchas veces, tal vez no sea querido o apreciado, pero siempre será respetado y valorado por los demás. Sobre este fundamento de su vida personal, aprenderá también a ejecutar, con efectividad creciente, las tareas específicas de un evangelista apasionado en cumplir la misión. Frente al desafío que le presenta la posmodernidad, será un evangelista cuidadoso de las buenas nuevas; frente al reto de construir puentes hacia la cultura local, responderá haciéndose un evangelista apasionado y disciplinado en la predicación bíblica; y, frente al desafío de la hora en que vivimos, será un evangelista con una vida consagrada y de servicio creciente. Sin embargo, su deseo es servir al pueblo de Dios busque, por sobre todas las obligaciones, mantener viva y vital su relación personal con Jesús, ya que hacer evangelismo no es una actividad sino una vida que se comparte. ${ }^{28} \mathrm{Si}$ se presenta el mensaje con el método de Dios, se logrará que la verdad cause una profunda impresión en los oyentes. El mensaje no debe ser presentado como una teoría sin vida, sino como una fuerza viva para trasformar vidas, a fin de enseñar, instruir y persuadir a hombres y mujeres, porque el evangelismo requiere que haya comunicación a través del estilo de vida, por la palabra y por los hechos. ${ }^{28}$

28 J. O. Sánchez, El líder del siglo XXI (Miami, FL: Editorial Unilit, 2001), 264. 